\title{
Opioid Peptides Inhibit Excitatory But Not Inhibitory Synaptic Transmission in the Rat Dorsal Motor Nucleus of the Vagus
}

\author{
Kirsteen N. Browning, ${ }^{1}$ Alexander E. Kalyuzhny, ${ }^{2}$ and R. Alberto Travagli ${ }^{1}$ \\ ${ }^{1}$ Division of Gastroenterology and Department of Physiology, University of Michigan Medical Center, Ann Arbor, Michigan \\ 48109-0682, and 2Department of Neuroscience, University of Minnesota, Minneapolis, Minnesota 55455
}

Opioid peptides produce gastrointestinal inhibition and increase feeding when applied to the brainstem. The present studies were designed to determine the actions of opioid peptides on synaptic transmission within the dorsal motor nucleus of the vagus (DMV) and the localization of $\mu$-opioid receptors. Whole-cell recordings were made from identified gastrointestinalprojecting DMV neurons in thin brainstem slices of the rat. Electrical stimulation of the nucleus of the tractus solitarius evoked EPSCs and IPSCs. In all neurons tested, methionine (Met)enkephalin (0.003-30 $\mu \mathrm{M})$ inhibited the peak amplitude of the EPSCs. The effect was prevented by naloxone $(1 \mu \mathrm{M})$ as well as by naloxonazine $(0.2 \mu \mathrm{M})$. An increase in the ratio of the evoked paired pulses indicated that the inhibition was attributable to actions at presynaptic receptors. This presynaptic inhibitory action was mimicked by [D-Ala ${ }^{2}, N$-Me-Phe ${ }^{4}$, Gly ${ }^{5}$-ol]-enkephalin $(0.1 \mu \mathrm{M})$ and the analgesic dipeptide kyotorphin $(10 \mu \mathrm{M})$ but not by cyclic [D-
Pen ${ }^{2}$, D-Pen ${ }^{5}$-enkephalin $(1 \mu \mathrm{M})$ and trans-3,4-dichloro- $N$ methyl- $N$-[2-(1-pyrrolidinyl)-cyclohexyl]benzeneacetamide methanesulfonate $(1 \mu \mathrm{M})$. In contrast, the amplitude of evoked IPSCs was not altered either by Met-enkephalin or by any of the opioid receptor-selective agonists. Immunohistochemical studies revealed that nerve terminals apposing DMV neurons showed immunoreactivity to $\mu$-opioid receptors colocalized with glutamate immunoreactivity but not glutamic acid decarboxylase immunoreactivity. These results suggest that within the DMV, $\mu$-opioid receptors are present on the nerve terminals of excitatory but not inhibitory inputs to Gl motoneurons. Such specificity may imply that the central inhibitory action of opioid peptides on gastrointestinal function targets selected pathways.

Key words: dorsal motor nucleus of the vagus; opioids; dorsal vagal complex; gastrointestinal function; immunoreactivity; feeding
In the rat brainstem, discrete subnuclei of the nucleus tractus solitarius (NTS) receive sensory information from the gastrointestinal (GI) tract and from higher centers involved in the regulation of GI function. NTS neurons project to the dorsal motor nucleus of the vagus (DMV) using primarily GABA and glutamate as neurotransmitters (Travagli et al., 1991). In physiological conditions, the NTS provides a predominantly GABAergic inhibitory input to the DMV that exerts a tonic inhibition of excitatory cholinergic pathways (Travagli et al., 1991; McCann and Rogers, 1992; Rogers et al., 1995, 1999; Sivarao et al., 1998). Although a robust glutamate innervation is also present in the NTS-DMV synapse (Travagli et al., 1991; Travagli and Gillis, 1994; Willis et al., 1996), it does not seem to be tonically active (Travagli et al., 1991, 1992; Travagli and Gillis, 1994; Willis et al., 1996; Sivarao et al., 1998). The DMV, then, provides the parasympathetic motor output to the GI tract via vagal efferent fibers comprising two distinct pathways, a cholinergic (excitatory) and a nonadrenergicnoncholinergic (NANC; inhibitory) pathway (Gillis et al., 1989).

Activation of central opioid receptors, particularly $\mu$-opioid receptors, induces gastric relaxation, decreases gastric acid secre-

\footnotetext{
Received Nov. 30, 2001; revised Jan. 9, 2002; accepted Jan. 10, 2002.
}

This manuscript was supported by National Institutes of Health Grant DK55530. We thank Dr. R. Elde (University of Minnesota) for providing MOR1 antiserum, Dr. A. Beitz (University of Minnesota) for providing antibodies to label glutamatergic neurons, and Drs. R. A. Gillis (Georgetown University, Washington, DC), C. Owyang (University of Michigan), and R.C. Rogers (Pennington Biomedical Research Center, Baton Rouge, LA) for comments on previous versions of this manuscript.

Correspondence should be addressed to Dr. R. Alberto Travagli, University of Michigan, 6520 Medical Science Research Building I, 1150 West Medical Center Drive, Ann Arbor, MI 48109-0682. E-mail: travagli@umich.edu.

Copyright (C) 2002 Society for Neuroscience $0270-6474 / 02 / 222998-07 \$ 15.00 / 0$ tion, inhibits intestinal transit, and increases feeding (Burks et al., 1987; Del Tacca et al., 1987; Fox and Burks, 1988; Gue et al., 1989; Kotz et al., 1997; Giraudo et al., 1998). Although some of these effects can be attributed to activation of areas outside the brainstem, evidence also points to an involvement of opioid neurotransmission in the dorsal vagal complex (DVC; i.e., DMV and NTS) originating either from local NTS neurons or from neurons in the amygdala or periaqueductal gray (Morilak et al., 1989; Pickel et al., 1989; Maley, 1996; Farkas et al., 1997; Giraudo et al., 1998; Liubashina et al., 2000).

The brainstem opioid system seems to be involved primarily in the regulation of feeding behavior. In fact, microinjection of $\mu$-opioid antagonists in the NTS decreases feeding induced either by deprivation, by stimulation of the amygdala, or by microinjection of neuropeptide $\mathrm{Y}$ in the paraventricular nucleus of the hypothalamus (Kotz et al., 1997; Giraudo et al., 1998; Kotz et al., 2000), whereas microinjections in the NTS of $\mu$-opioid agonists increase feeding (Kotz et al., 1997; Giraudo et al., 1998). In contrast, the role of opioids in the brainstem control of GI motility is still controversial. In fact, although microinjections of naloxone in the DVC do not affect gastric relaxation per se, thus suggesting that opiate receptors may not be involved in its physiological control (Gue et al., 1989), other groups have provided evidence that microinjection of opioids in the DVC does indeed decrease gastric motility (Krowicki et al., 1999) (R. A. Gillis, unpublished data).

Although it is clear that opioid peptides can exert multiple actions within the DVC, their precise action on neurons involved in GI function is still unclear. The aims of this study were twofold: (1) to assess the actions of opioid peptides on synaptic 
transmission to identified gastric-projecting DMV neurons and (2) to test for the presence of opioid receptors on the synaptic terminals within the DVC.

Preliminary accounts of this work have been presented previously in abstract form (Browning and Travagli, 2000).

\section{MATERIALS AND METHODS}

Retrograde tracing. Gastric-projecting neurons of the DMV were labeled with the fluorescent retrograde neuronal tracer 1,1'-dioctadecyl-3,3,3', $3^{\prime}$ tetramethylindocarbocyanine perchlorate $\left[\mathrm{DiIC}_{18}(3)\right.$; DiI] as described previously (Browning et al., 1999). Briefly, 12-d-old rat pups of either sex were anesthetized deeply with halothane (abolition of the foot pinch withdrawal reflex) before the head of the rat was placed in a custommade anesthetic chamber through which halothane mixed with air was pumped $(400-600 \mathrm{ml} / \mathrm{min})$, in accordance with veterinary guidelines. The entire abdominal area was shaved and cleaned with ethanol before an abdominal laparotomy was performed. Crystals of DiI were applied to one gastric region per rat, either to the major curvature of the fundus or corpus or to the antrum/pylorus. The application site was embedded in a fast-hardening epoxy compound that was allowed to harden for several minutes before the entire surgical area was washed with warm, sterile saline. The laparotomy was closed with $5 / 0$ suture, and the animal was allowed to recover for $10-15 \mathrm{~d}$.

Electrophysiological recording. On the day of the experiment, the rat was anesthetized deeply with halothane (abolition of the foot pinch withdrawal reflex) before being killed by a bilateral pneumothorax. The brainstem was removed and placed into chilled, oxygenated Krebs' solution (see below for composition). Using a vibratome, six to eight coronal slices (200 $\mu \mathrm{m}$ thick) of the brainstem containing the DMV were cut. The slices were incubated for at least $1 \mathrm{hr}$ at $32^{\circ} \mathrm{C}$ in oxygenated Krebs' solution before use. A single slice was transferred to a custom-made perfusion chamber (volume $500 \mu \mathrm{l}$ ) and kept in place with nylon mesh. The chamber was maintained at $35^{\circ} \mathrm{C}$ by perfusion with warmed Krebs' solution at a rate of $2.5-3.0 \mathrm{ml} / \mathrm{min}$.

Electrophysiological recordings were made from retrogradely labeled DMV neurons only, identified using a Nikon (Tokyo, Japan) E600FS microscope fitted with tetramethylrhodamine isothiocyanate (TRITC) epifluorescent filters. Once the identity of the labeled neuron was confirmed, recordings were made under bright-field illumination using differential interference contrast (Nomarski) optics.

Whole-cell patch-clamp recordings were made with patch pipettes filled with a potassium gluconate intracellular solution (see below for solution composition) using a single-electrode voltage-clamp amplifier (Axopatch 1D; Axon Instruments, Union City, CA). Data were filtered at $2 \mathrm{kHz}$, digitized via a Digidata $1200 \mathrm{C}$ interface (Axon Instruments, Union City, CA), acquired, and stored on a PC using pClamp8 software (Axon Instruments). Only those recordings having a series resistance of $<15 \mathrm{M} \Omega$ were accepted. Data analysis was performed using pClamp8 software.

Drugs were applied to the bath (at a concentration shown in the literature to be effective) via a series of manually operated values. Results are expressed as mean \pm SEM. Neurons were allowed to recover fully between additions of agonists (minimum washout period of $10 \mathrm{~min}$ ). Antagonists were superfused for at least $10 \mathrm{~min}$ before reapplication of the agonist. Each neuron served as its own control when the effects of antagonists were assessed (i.e., in each neuron the effect of any drug was assessed before and after antagonist using Student's $t$ test with significance set as $p<0.05$ ).

Electrical stimulation. To evoke synaptic currents in the recorded DMV neuron, tungsten bipolar stimulating electrodes (WPI Ltd, Sarasota, FL) were placed in the centralis or medialis subnuclei of the NTS. Pairs of stimuli $(0.05-1.0 \mathrm{msec} ; 10-500 \mu \mathrm{A} ; 50-250 \mathrm{msec}$ apart) were applied every $20 \mathrm{sec}$ to evoke submaximal IPSCs and EPSCs.

Immunohistochemistry. Rats were injected with Fluorogold (Fluorochrome, Englewood, CO) $(20 \mu \mathrm{g} / \mathrm{ml}$ saline per rat, i.p. $)$ to label vagal preganglionic neurons innervating the subdiaphragmatic viscera, thus allowing delineation of the boundaries of the DMV (Fox and Powley, 1985; Zheng et al., 1999; Guo et al., 2001). After 3 d, the rats were anesthetized with urethane $(1.2 \mathrm{gm} / \mathrm{kg}$, i.p. $)$ and perfused transcardially with $400 \mathrm{ml}$ of saline followed by $400 \mathrm{ml}$ of a PBS solution containing $4 \%$ paraformaldehyde. The brainstem was then extracted and stored overnight at $4^{\circ} \mathrm{C}$ in PBS-paraformaldehyde. The brainstem was subsequently rinsed and stored in PBS containing $2.5 \%$ sucrose for $3 \mathrm{~d}$ (with daily changes of the PBS-sucrose solution).
Coronal sections through the DVC were cut at the level of the area postrema using a Bright cryostat (Huntington, UK) at a nominal thickness of $5 \mu \mathrm{m}$. The diluent used for all antibodies was $0.1 \mathrm{M}$ PBS, $\mathrm{pH} 7.4$, containing $1 \%$ BSA, $1 \%$ normal donkey serum, $0.3 \%$ Triton $\mathrm{X}-100$, and $0.01 \%$ sodium azide. Sections were double-stained with rabbit antisera directed against the cloned $\mu$-opioid receptor (MOR1; 1:600 dilution) (Arvidsson et al., 1995) combined either with a mouse monoclonal antibody against glutamic acid decarboxylase (GAD-6; 1:200 dilution) or with mouse monoclonal antibody against $\gamma$-glutamylglutamate $(1: 10,000$ dilution) (Beitz et al., 1986).

Sections were incubated overnight at $4^{\circ} \mathrm{C}$, washed in PBS (three times for $15 \mathrm{~min}$ ) at room temperature, and incubated for $1 \mathrm{hr}$ at room temperature with secondary antibodies. The secondary antibodies used were donkey anti-rabbit conjugated with cyanine 3.18 (Cy3, 1:100; MOR1 staining) and donkey anti-mouse conjugated with fluorescein isothiocyanate (FITC, 1:100; GAD-6 and glutamate staining).

Conventional wide-field microscopy was used to collect images of cells labeled with Fluorogold (330-390 nm excitation and a $420 \mathrm{~nm}$ long-pass emission). Conventional digital microscopic images were collected using a Cohu model 4915 CCD camera (San Diego, CA), a Power Macintosh 7100 computer equipped with a frame buffer (model LG-3; Scion Corporation, Frederick, MD), and Scion Corporation's version of the public domain NIH-Image program (developed at the National Institutes of Health and available from the Internet by anonymous FTP from zippy. nimh.nih.gov or on floppy disk from the National Technical Information Service, Springfield, VA, part number PB95-500195GEI).

Confocal microscopic images were collected using an MRC 1024 confocal scanning laser microscope equipped with a $\mathrm{Kr} / \mathrm{Ar}$-ion laser. The microscope was equipped with filters for the selective visualization of $\mathrm{Cy} 3$ and FITC. If stained with FITC, sections were mounted with a PBS/glycerol solution containing $0.1 \%$ phenylenediamine to reduce fading (Johnson and Nogueira-Araujo, 1981); if not stained with FITC, sections were mounted with DPX (Fluka, Ronkonkoma, NY).

Qualitative analysis was conducted to identify labeled terminals apposing DMV neurons. Terminals were defined as colocalizing MOR1 and glutamate or MOR1 and GAD-6 if labeling for the corresponding antibodies was present in profiles with similarities in size and geometry that overlap during superimposition of the images obtained with the appropriate fluorescent filters (TRITC for MOR1 and FITC for glutamate or GAD-6). The resulting images were merged, and colocalization was determined by the appearance of yellow coloration obtained by combination of the TRITC red image with the FITC green image from the labeled terminals.

Drugs and solutions. Krebs' solution consisted of (in mM): $126 \mathrm{NaCl}, 25$ $\mathrm{NaHCO}_{3}, 2.5 \mathrm{KCl}, 1.2 \mathrm{MgCl}_{2}, 2.4 \mathrm{CaCl}_{2}, 1.2 \mathrm{NaH}_{2} \mathrm{PO}_{4}$, and 11 dextrose, maintained at a pH of 7.4 by bubbling with $\mathrm{O}_{2}-\mathrm{CO}_{2}(95 \%-5 \%)$.

Intracellular solution consisted of (in $\mathrm{mM}$ ): $128 \mathrm{~K}$-gluconate, $10 \mathrm{KCl}$, $0.3 \mathrm{CaCl}_{2}, 1 \mathrm{MgCl}_{2}, 10 \mathrm{HEPES}, 1 \mathrm{EGTA}, 2 \mathrm{Na}-\mathrm{ATP}$, and $0.25 \mathrm{Na}-\mathrm{GTP}$, adjusted to a $\mathrm{pH}$ of 7.35 with $\mathrm{KOH}$.

DiI was purchased from Molecular Probes (Eugene, OR); all secondary antibodies were obtained from Jackson ImmunoResearch Laboratories, Inc. (West Grove, PA); MOR1 antiserum was a generous gift of Dr. Bob Elde (University of Minnesota, Minneapolis, MN); and antibodies to label glutamatergic neurons were a generous gift of Dr. Al Beitz (University of Minnesota, Minneapolis, MN).

GAD-6 was produced by the Developmental Studies Hybridoma Bank Molecular Sciences, Johns Hopkins University School of Medicine (Baltimore, MD) and by the Department of Biological Sciences, University of Iowa (Iowa City, IA) under contract N01-HD-6-2915 from the National Institute of Child Health and Human Development. [D-Ala ${ }^{2}$, $N$-Me-Phe ${ }^{4}$, Gly-ol ${ }^{5}$-enkephalin (DAMGO); cyclic[D-Pen ${ }^{2}$, D-Pen ${ }^{5}$ enkephalin (DPDPE); trans-3,4-dichloro- $N$-methyl- $N$-[2-(1-pyrrolidinyl)cyclohexyl]benzeneacetamide methanesulfonate (U50,488), and all other chemicals were purchased from Sigma (St. Louis, MO).

\section{RESULTS}

Whole-cell patch-clamp recordings were made from 53 gastricprojecting rat DMV neurons. Neurons from the distinct regions did not differ, either qualitatively or quantitatively, in their responses to application of opioid receptor agonists or antagonists. All results, therefore, were combined. 




Figure 1. Effects of ME on EPSCs. A, Representative trace showing that perfusion with $\mathrm{ME}$ induces a concentration-dependent inhibition of the evoked EPSC. Each trace represents the average of at least three EPSCs. $V_{\text {hold }},-50 \mathrm{mV}$. B, Concentration-response curve showing the ME-induced inhibition of the EPSC amplitude. The $\mathrm{EC}_{50}$ was $0.35 \mu \mathrm{M}$. Each point of the curve represents the average of 4-16 data points.

\section{Effects of opioid peptides on excitatory synaptic transmission}

EPSCs were evoked by electrical stimulation of the NTS in 38 gastric-projecting DMV neurons. The nonselective opioid receptor agonist methionine (Met)-enkephalin (ME; 0.003-30 $\mu \mathrm{M}$ ) induced a concentration-dependent inhibition in evoked EPSC amplitude in all 21 neurons tested (Fig. $1 A$ ) with an estimated $\mathrm{IC}_{50}$ of $0.35 \mu \mathrm{M}$ (Fig. $1 B$ ).

\section{Opioids acted presynaptically to inhibit evoked EPSC amplitude}

The ratio of the amplitude of two postsynaptic currents evoked a few milliseconds apart is used to determine whether a drug is acting at a presynaptic or postsynaptic site, with a change in the ratio being taken as indicative of a presynaptic site of action (Travagli and Williams, 1996; Browning and Travagli, 1999, 2001).

When two EPSCs were evoked 50-200 msec apart, ME decreased the amplitude of the first current $(\mathrm{C} 1)$ more relative to that of the second current $(\mathrm{C} 2)$, such that the paired-pulse ratio $(\mathrm{C} 2 / \mathrm{C} 1)$ increased. For example, in the presence of $10 \mu \mathrm{M} \mathrm{ME}$, the paired-pulse ratio increased from $0.97 \pm 0.12$ to $1.79 \pm 0.20$ $(n=12 ; p<0.05$; Fig. 2).

\section{The opioid-induced inhibition of evoked EPSC amplitude occurs via actions at $\mu$-opioid receptors only}

In all of the neurons tested, the inhibition of EPSC amplitude induced by $10 \mu \mathrm{M} \mathrm{ME}$ was prevented by superfusion with the nonselective opioid receptor antagonist naloxone $(1 \mu \mathrm{M})$. In the presence of $10 \mu \mathrm{M} \mathrm{ME}$, the amplitude of the evoked EPSC was reduced from $277 \pm 81.0$ to $54 \pm 11.2 \mathrm{pA}$ (i.e., a $78 \pm 7.0 \%$ reduction; $n=4 ; p<0.05)$. Pretreatment with naloxone reduced the ME-induced inhibition of EPSC amplitude from $78 \pm 7 \%$ to $1 \pm 6.6 \%(n=4 ; p<0.05$; Fig. $3 A)$. Similarly, in a different group of neurons, pretreatment with the $\mu$-opioid receptor-selective antagonist naloxonazine $(0.2 \mu \mathrm{M})$ attenuated the ME-induced reduction in evoked EPSC amplitude from $76 \pm 6.5 \%$ to $2 \pm$ $8.9 \%(n=5 ; p<0.05$; Fig. $3 B)$.

In addition, the $\mu$-opioid receptor-selective agonist DAMGO $(0.1 \mu \mathrm{M})$ reduced evoked EPSC amplitude from $230 \pm 52.9$ to $105 \pm 26.2 \mathrm{pA}$ (i.e., a $55 \pm 7.5 \%$ reduction; $n=6$; $p<0.05$ ).
A
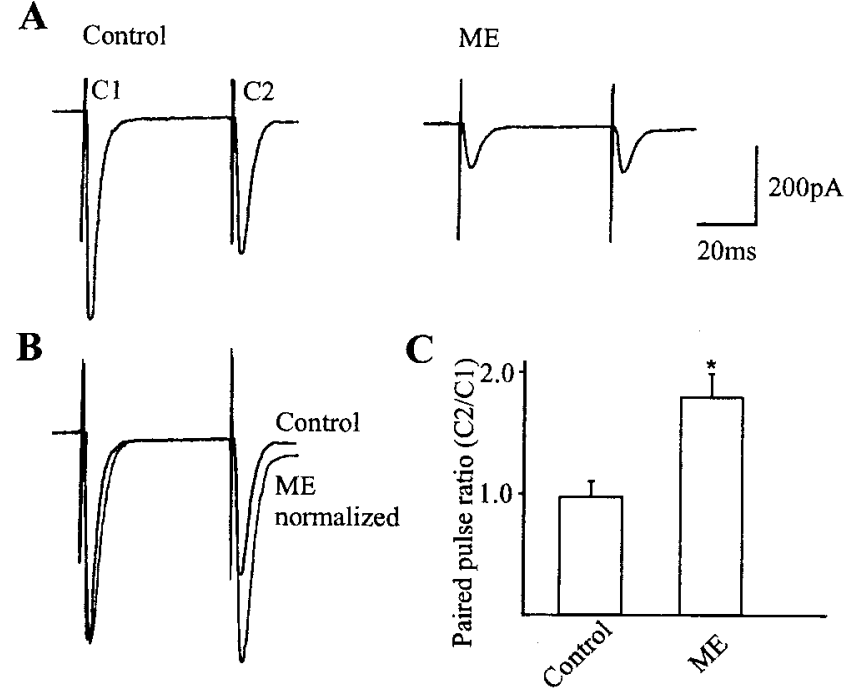

Figure 2. Inhibition of the EPSC by Met-enkephalin is accompanied by a change in the paired-pulse ratio. $A$, Representative traces showing pairs of EPSCs evoked $120 \mathrm{msec}$ apart. ME $(10 \mu \mathrm{M})$ decreased the amplitude of the evoked currents. $B$, Paired-pulse ratio for traces in $A$. The alteration of the paired-pulse ratio by ME can be observed more readily after normalizing to control amplitude the amplitude of the EPSC evoked by the first pulse $(\mathrm{Cl})$. Traces are the average of three to six originals each. Holding potential was $-50 \mathrm{mV}$. $C$, The paired-pulse ratio compares the amplitude of the second current $(C 2)$ with that of the first current $(C 1)$. Note that the paired-pulse ratio obtained from averaging all of the traces in the presence of ME is larger than the paired-pulse ratio obtained from traces obtained under control conditions. ${ }^{*} p<0.05$.
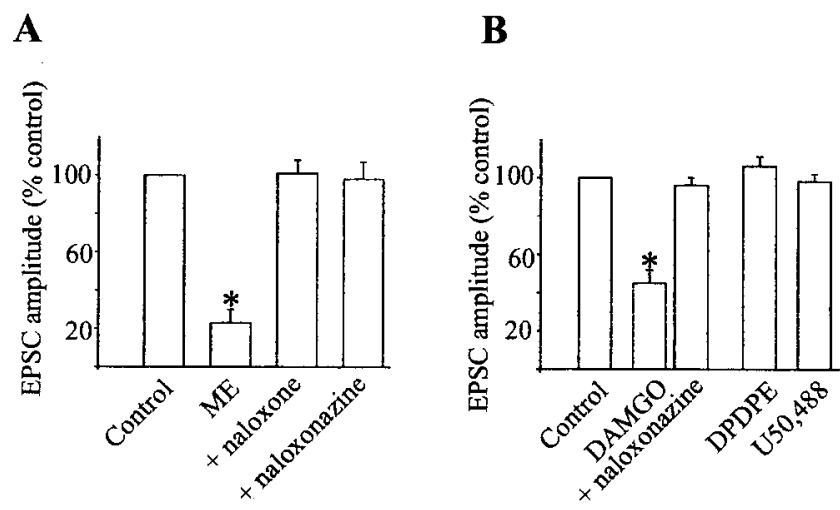

Figure 3. Inhibition of EPSCs by exogenous opioids is mediated by activation of $\mu$-opioid receptors. $A$, Summarized results showing that the inhibition of the evoked EPSC by ME $(10 \mu \mathrm{M} ; n=16)$ is attenuated by pretreatment with naloxone $(1 \mu \mathrm{M} ; n=4)$ as well as by pretreatment with naloxonazine $(0.2 \mu \mathrm{M} ; n=5)$. $B$, Summarized results showing that the inhibition of the evoked EPSC by ME $(10 \mu \mathrm{M})$ is mimicked by DAMGO $(0.1 \mu \mathrm{M} ; n=6)$ but not by DPDPE $(1 \mu \mathrm{M} ; n=6)$ or U50,488 $(1 \mu \mathrm{M} ; n=$ $6)$. The DAMGO-mediated inhibition of the EPSCs was antagonized by pretreatment with naloxonazine $(0.2 \mu \mathrm{M} ; n=6)$. ${ }^{*} p<0.05$.

Pretreatment with the selective $\mu$-opioid receptor antagonist naloxonazine $(0.2 \mu \mathrm{M})$ attenuated the DAMGO response to a $3 \pm$ $4.3 \%$ inhibition $(n=6 ; p<0.05)$. In contrast, neither the $\delta$-opioid receptor-selective agonist DPDPE $(1 \mu \mathrm{M})$ nor the $\kappa$-opioid receptor-selective agonist U50,488 $(1 \mu \mathrm{M})$ had any effect on the amplitude of the evoked EPSC $(106 \pm 5 \%$ and $97.8 \pm 4 \%$ of control; $n=6$ for both; $p>0.05$, respectively; Fig. $3 C$ ). 

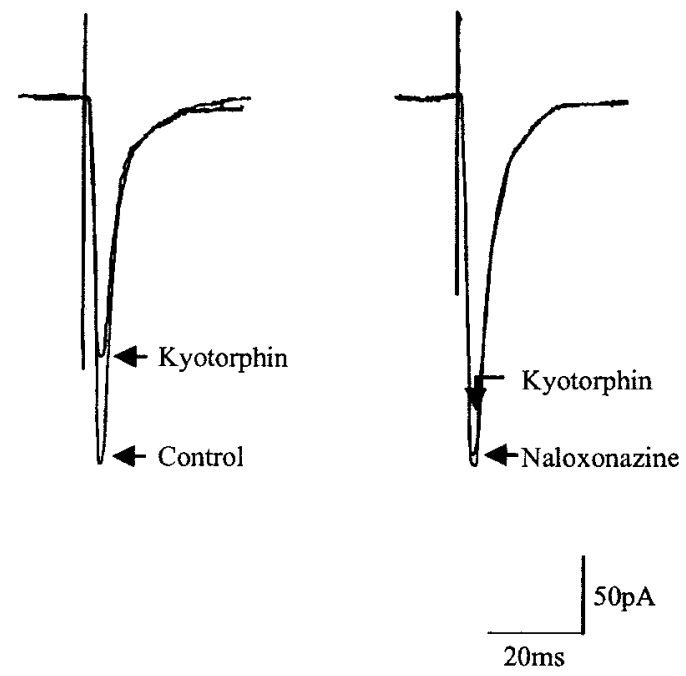

Figure 4. Inhibition of glutamate EPSCs by endogenous opioids is also mediated by activation of $\mu$-opioid receptors. The representative trace on the left shows that perfusion with the dipeptide kyotorphin $(10 \mu \mathrm{M} ; n=$ 8 ) induces an inhibition of the evoked EPSC. The kyotorphin-induced inhibition was attenuated by pretreatment with naloxonazine $(0.2 \mu \mathrm{M} ; n=$ 6 ), as shown on the right. Each trace represents the average of at least three EPSCs. $V_{\text {hold }},-50 \mathrm{mV}$.

\section{Kyotorphin reduces evoked EPSC amplitude}

The analgesic dipeptide kyotorphin has been demonstrated to promote the release of ME from nerve terminals with a mechanism independent of binding to the opioid receptors (Shiomi et al., 1981; Rackham et al., 1982; Hirai and Katayama, 1985; Ueda et al., 1986). In the present experiments, perfusion with kyotorphin $(10 \mu \mathrm{M})$ reduced the amplitude of the evoked EPSC from $331 \pm 82.4$ to $261 \pm 57.2$ pA (i.e., a $20 \pm 3.0 \%$ inhibition; $n=8$; $p<0.05)$. As with ME, the reduction in EPSC amplitude was accompanied by an increase in the paired-pulse ratio from $0.67 \pm$ 0.08 to $1.04 \pm 0.18(n=7 ; p<0.05)$.

Pretreatment with the $\mu$-opioid receptor-selective antagonist naloxonazine attenuated the presynaptic inhibitory action of kyotorphin. In the presence of naloxonazine, the kyotorphin-induced decrease of evoked EPSC amplitude was reduced to $0 \pm 3.2 \%$ (from $225 \pm 27$ to $245 \pm 33 \mathrm{pA} ; n=6 ; p<0.05$; Fig. 4).

\section{Opioid peptides do not attenuate inhibitory synaptic transmission}

Perfusion with $10 \mu \mathrm{M} \mathrm{ME}$ did not affect the amplitude of evoked IPSCs. In fact, the amplitude of the evoked IPSC decreased from $202 \pm 16$ to $195 \pm 15$ pA (i.e., a $3 \pm 2 \%$ reduction; $n=8 ; p>$ $0.05)$. Similarly, neither the $\mu$-opioid receptor-selective agonist DAMGO $(0.1 \mu \mathrm{M})$, the $\delta$-opioid receptor-selective agonist DPDPE $(0.1 \mu \mathrm{M})$, nor the $\kappa$-receptor-selective agonist U50,488 $(0.1 \mu \mathrm{M})$ altered the amplitude of evoked IPSCs $(98 \pm 2 \%, 100 \pm$ $3 \%$, and $99 \pm 2 \%$ of control, respectively; $n=6 ; p>0.05$ in each instance; Fig. 5).

\section{Postsynaptic response to opioid peptides in GI projecting neurons}

Of the 21 GI-projecting DMV neurons to which ME was applied, a concentration-dependent outward current was observed in 14 neurons (i.e., 67\%). Perfusion with $10 \mu \mathrm{M}$ ME induced a $32 \pm 4.7$ pA outward current that was abolished by pretreatment with the nonselective opioid receptor antagonist naloxone $(1 \mu \mathrm{M})$. Furthermore, in four of these neurons, the ME-induced outward
A



B



Figure 5. Perfusion with opioid agonists does not affect the amplitude of evoked IPSCs. $A$, Representative trace showing that perfusion with ME $(10 \mu \mathrm{M} ; n=8)$ does not induce an inhibition of the evoked IPSC. The trace represents the average of at least three IPSCs. $V_{\text {hold }},-50 \mathrm{mV} . B$, Summarized results showing that the evoked IPSC is unaffected by perfusion with DAMGO $(0.1 \mu \mathrm{M} ; n=6)$, DPDPE $(1 \mu \mathrm{M} ; n=6)$, or U50,488 (1 $\mu \mathrm{M} ; n=6)$.

current was reduced from $40 \pm 12.4$ to $0 \pm 2.9 \mathrm{pA}$ in naloxonazine $(n=4 ; p<0.05)$. Similarly, perfusion with the selective $\mu$-opioid receptor agonist DAMGO $(0.1 \mu \mathrm{M})$ induced an outward current of $21 \pm 1 \mathrm{pA}$ in three of eight neurons tested (i.e., 37\%); the outward current was abolished by pretreatment with the selective $\mu$-opioid receptor antagonist naloxonazine $(0.2 \mu \mathrm{M})$.

In contrast, neither the $\delta$-opioid receptor-selective agonist DPDPE $(1 \mu \mathrm{M})$ nor the $\kappa$-opioid receptor-selective agonist U50,488 $(1 \mu \mathrm{M})$ had any effect on the DMV membrane $(n=6$ for both).

\section{Immunohistochemistry}

In the five rats analyzed, we observed prominent MOR1 labeling in the NTS, particularly in the subnucleus commissuralis and the area subpostrema (Fig. 6B). Unlike MOR1, GAD immunoreactivity (GAD-IR) was confined to punctate structures (Fig. 6C,F) within the NTS and the DMV, resembling the labeling pattern reported previously (D'Amelio et al., 1987; Kalyuzhny and Wessendorf, 1997). Glutamate-like (Glu)-IR, instead, was more diffuse than GAD-IR and seemed to be present in terminals resembling synaptic contacts (Fig. 6D). When the brainstem sections were analyzed qualitatively for appositions between the immunostained terminals and the Fluorogold-labeled DMV neurons, Glu-IR was observed in NTS profiles resembling cell processes and varicosities (Fig. 6D). In many parts of the DMV, the profiles labeled for MOR1 also appeared to be positive for Glu-IR (Fig. $6 D)$. Conversely, no instance of colocalization of MOR1 and GAD-IR in nerve terminals was found (Fig. 6F). Indeed, GAD-IR varicosities of the NTS appear to appose MOR1-IR profiles and may represent afferent terminals of GABAergic neurons onto DMV neurons expressing MOR1 (Fig. $6 F$ ). If this is the case, it may be suggested that GABAergic neurons of the NTS enhance the inhibitory effects of opiates that act through $\mu$-receptors on the DMV postsynaptic neurons.

A proposed scheme of some of the connections within the DVC is depicted in Figure 7.

\section{DISCUSSION}

In this study, we have shown that opioid peptides attenuate excitatory but not inhibitory synaptic transmission to gastricprojecting DMV motor neurons via interactions with presynaptic $\mu$-opioid receptors. Furthermore, opioid peptides hyperpolarize a subpopulation of DMV neurons via activation of postsynaptic 

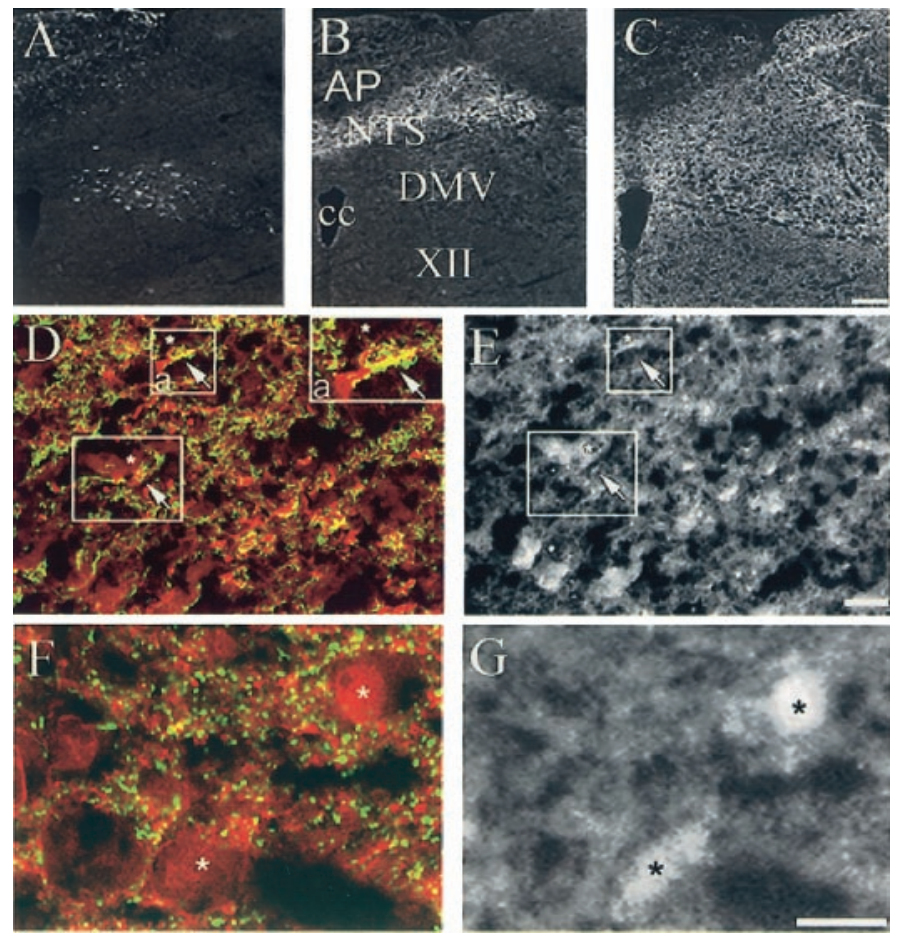

Figure 6. Labeling for the cloned MOR1 is colocalized with Glu-IR but not with GAD-IR. $A$, Low-magnification micrograph of a coronal section of the brainstem through the intermediate portion of the NTS photographed with UV filters. Note the Fluorogold-labeled DMV neurons are located lateral to the central canal $(c c)$. Some Fluorogold-stained cells are also present in the area postrema $(A P)$ located dorsal to the central canal. $B$, Same field of view as in $A$, but viewed through TRITC filters to reveal the dense MOR1-IR in the subpostremal area of the NTS. XII, Nucleus of the hypoglossus. $C$, Same field of view as in $A$, but viewed through FITC filters to reveal the punctate GAD-IR present throughout the DVC. $D$, Composite image depicting MOR1-IR (TRITC filters, red) and Glu-IR (FITC filters, green) in the DMV. Note the colocalization of MOR1-IR and Glu-IR (arrows; yellow) in close apposition to Fluorogoldlabeled DMV neurons (asterisks and depicted in $E$ ). The inset $a$ at the top right is a magnification of the area enclosed by the square box $(a)$ in the same panel. Note also the intense MOR1-IR staining of the two DMV neurons enclosed by the rectangle. E, Same field of view as in $D$, but viewed through UV filters to reveal the Fluorogold-stained DMV neurons. Two of these neurons (indicated by asterisks) are apposed by terminals that show colocalization of MOR1-IR and Glu-IR ( $D$ and $E$, arrows). $F$, Composite image depicting MOR1-IR (TRITC filters, red) and GAD-IR (FITC filters, green) in the DMV. Note that MOR1-IR and GAD-IR are not colocalized. Asterisks indicate the Fluorogold-labeled DMV neurons in $G$. Note also the intense MOR1-IR staining of the DMV neurons indicated by the asterisks. $G$, Same field of view as in $F$, but viewed through UV filters to reveal the Fluorogold-stained DMV neurons. Two of these neurons (indicated by asterisks) are apposed by terminals that do not show colocalization of MOR1-IR and GAD-IR $(F)$. Scale bars: $A-C, 100 \mu \mathrm{m} ; E-G, 25 \mu \mathrm{m}$.

$\mu$-opioid receptors. This electrophysiological evidence is supported by immunohistochemical data indicating that MOR1-IR is present on terminals of glutamate-containing NTS neurons but not on terminals of GAD-containing NTS cells apposing DMV neurons. The GAD-containing terminals, instead, seem to appose MOR1-IR DMV neurons. Such specificity may imply that the central inhibitory action of opioid peptides on GI function targets selected pathways.

The present data provide the in vitro evidence to the in vivo observation that application of $\mu$-opioid receptor agonists in the $\mathrm{CNS}$, including the brainstem, inhibit gastric motility and tone

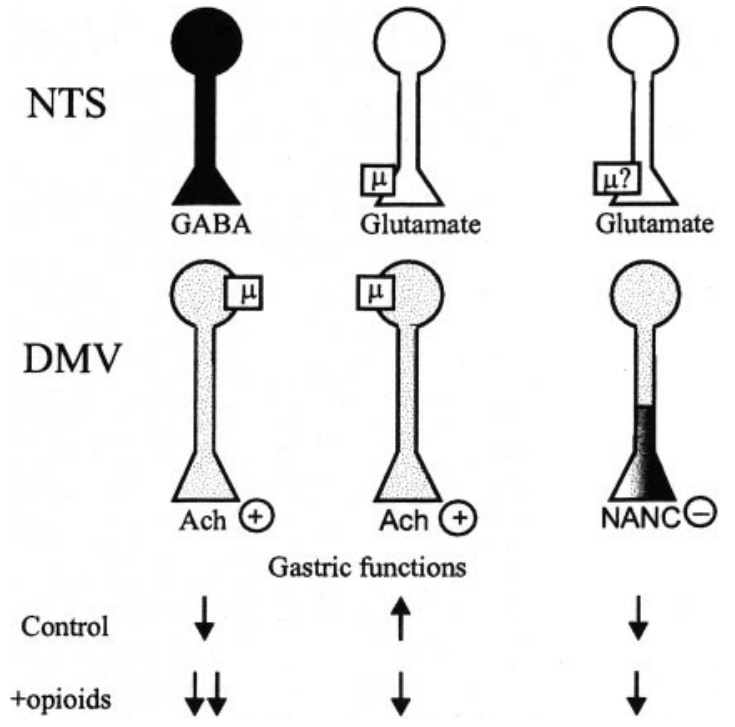

Figure 7. Proposed scheme of the synaptic connections between NTS and DMV that are modulated by $\mu$-opioid receptors. Neurons of the NTS, using glutamate and GABA as their main neurotransmitters, convey sensory information to neurons of the DMV, which, by means of cholinergic (Ach; excitatory) or NANC (inhibitory) vagal efferent pathways, controls the functions of the subdiaphragmatic upper GI tract. One type of circuit, probably controlled by GABAergic NTS neurons, tonically limits the cholinergic vagal output. A second type of circuit, possibly innervated by glutamatergic NTS neurons, activates subsets of cholinergic DMV neurons. A third pathway, probably controlled by a different subset of glutamatergic NTS neurons, activates an inhibitory NANC path to the gut. In normal conditions, these circuits set the tone and motility of the GI tract. We hypothesize that opioids within the DVC remove the glutamatergic input to cholinergic fibers and hyperpolarize excitatory DMV neurons; the combination of these dual effects of opioids in the DVC would result in a robust gastroinhibition. We would further surmise that the DMV neurons that are unaffected by opioids are the ones that control the NANC inhibitory pathway to the GI tract. The arrow pointing up indicates an increase; arrows pointing down indicate a decrease.

and increase feeding (Burks et al., 1987; Del Tacca et al., 1987; Fox and Burks, 1988; Gue et al., 1989; Kotz et al., 1997; Giraudo et al., 1998; Krowicki et al., 1999). Indeed, although in the in vivo studies mentioned evidence was provided to show that the opioidinduced effects on GI function were obtained via a vagally mediated pathway, these experiments did not identify either the brainstem nuclei or the circuitry involved. In this study, we show that the opioid-mediated actions are achieved via attenuation of excitatory synaptic transmission from the NTS to GI-projecting DMV neurons and via a direct hyperpolarization of a subpopulation of DMV neurons. The decrease in glutamate release from the NTS and the outward current in the DMV represent two cooperative mechanisms used by opioids to decrease the overall parasympathetic vagal activity.

In agreement with previous anatomic and functional studies (Bueno et al., 1985; Dashwood et al., 1988; Xia and Haddad, 1991; Mansour et al., 1995; Cheng et al., 1996; Ding et al., 1996; Pickel et al., 1998; Aicher et al., 2000; Huang et al., 2000), our electrophysiological data show that the responses of dorsal vagal neurons to opioids were mediated by interaction with $\mu$-opioid receptors only. In fact, the $\mathrm{ME}$ inhibition was mimicked by DAMGO, and both agonists were inhibited by naloxonazine. In contrast, neither DPDPE nor U50,488 had any effect either on the amplitude of evoked EPSCs or directly on the DMV membrane. Interestingly, in contrast to attenuation of the evoked EPSCs, 
inhibitory synaptic transmission from the NTS to the DMV was unaffected by opioid peptides, either by ME itself or by the $\mu$-, $\delta$-, or $\kappa$-opioid receptor-selective agonists.

Our dual-labeling immunohistochemical studies suggest an explanation for such distinct electrophysiological actions on synaptic transmission. In fact, assessing the location of MOR1 relative to that of glutamate- or GABA-immunoreactive profiles revealed that MOR1s were present only on glutamate-containing cell processes and varicosities, which may represent NTS nerve terminals apposing DMV neurons. Unlike MOR1, GAD-IR was confined to punctate structures of variable size, probably representing NTS axon terminals, and resembled the labeling pattern reported previously in other brainstem areas (D'Amelio et al., 1987; Kalyuzhny and Wessendorf, 1997). No examples of double-labeling for GAD and MOR1 were found throughout the examined regions of the DMV; rather, NTS varicosities containing GAD-IR appeared to appose MOR1-IR profiles of the DMV. It is likely that these appositions represent terminals of NTS GABAergic neurons onto DMV neurons expressing MOR1. If this is the case, it may be suggested that GABAergic neurons enhance the inhibitory effects of opiates that act through $\mu$-receptors on DMV postsynaptic neurons.

Thus, it would appear that the immunohistochemical evidence supports the electrophysiological data in suggesting that $\mu$-opioid receptors are present on the nerve terminals of excitatory but not inhibitory synapses within the DVC and that $\mu$-opioid receptors are located on postsynaptic DMV cells receiving GABAergic inputs from the NTS. A similar immunohistochemical distribution of MOR1 and GABA-containing terminals seems to be present in adjacent sympathetic areas in which GABAergic axon terminals rarely contained MOR1 (Aicher et al., 2001), although opioid peptides decrease both excitatory and inhibitory currents in the same area (Hayar and Guyenet, 1998).

The potential physiological importance of the opioid-mediated inhibition within the DVC is highlighted by the data obtained with the use of kyotorphin. Perfusion of the DVC with kyotorphin, which has been shown previously to selectively evoke the release of ME from nerve terminals (Shiomi et al., 1981; Hirai and Katayama, 1985; Ueda et al., 1986) without interaction with the opioid receptors (Rackham et al., 1982), resulted in an inhibition of the amplitude of evoked EPSCs. As with the actions of $\mathrm{ME}$ and DAMGO, the action of kyotorphin was reversed by naloxonazine. Hence, it would appear that within the rat DVC, kyotorphin induces the release of an endogenous $\mu$-opioid receptor-selective agonist that acts at presynaptic receptors to inhibit fast excitatory synaptic transmission.

The inhibitory effects of opioid peptides in the DVC were not limited to an inhibition of glutamatergic inputs from the NTS to the DMV. In fact, opioid peptides also inhibited directly a subpopulation of gastric-projecting DMV neurons via activation of $\mu$-opioid receptors only. In agreement with previous studies (Duan et al., 1990), we have shown that the ME-induced outward current was antagonized by naloxone and naloxonazine and mimicked by DAMGO, whereas neither DPDPE nor U50,488 had any postsynaptic actions on DMV neurons.

In this and previous studies, opioid peptides have been reported to inhibit both NTS and DMV neurons (Duan et al., 1990; Rhim and Miller, 1994; Rhim et al., 1996). This raises an apparent contradiction with respect to the overall brainstem effects of opioid peptides. For example, if the hyperpolarization of NTS neurons by opioid peptides was nonselective, the main effect would be an inhibition of the predominantly GABAergic synaptic transmission from the NTS to the DMV, which would then result in an overall excitatory output from the DMV. This is in contrast to the direct inhibitory or hyperpolarizing actions of opioid peptides on DMV neurons. In light of the present study, however, it would seem that regardless of the direct effects of opioid peptides on NTS neurons, their principal action on synaptic transmission between the NTS and the DMV is to inhibit excitatory but not inhibitory transmission, an action more in keeping with their overall effects within the DVC. These characteristics suggest that endogenous opiates may regulate very specific connections within the DVC, with their effect most likely depending on the relative strength of these inputs, which in turn depend on the particular afferent circuitry involved.

In summary, we have shown that the inhibition of opioid peptides in the DVC is targeted to selective pathways. It would appear that opioid peptides act to inhibit the vagal cholinergic drive by a combined inhibition at two sites: one consists of relieving the glutamatergic input to DMV cholinergic fibers and the other consists of directly inhibiting DMV cholinergic neurons.

The mechanisms of selective receptor targeting within a cell and its functional implications remain to be elucidated, but it may represent a way to modulate specific afferent input or encode patterns of afferent information that lead to distinct functional consequences for cellular activity (Aicher et al., 2001).

\section{REFERENCES}

Aicher SA, Goldberg A, Sharma S, Pickel VM (2000) $\mu$-Opioid receptors are present in vagal afferents and their dendritic targets in the medial nucleus tractus solitarius. J Comp Neurol 422:181-190.

Aicher SA, Schreihofer AM, Kraus JA, Sharma S, Milner TA, Guyenet PG (2001) $\mu$-Opioid receptors are present in functionally identified sympathoexcitatory neurons in the rat rostral ventrolateral medulla. J Comp Neurol 433:34-47.

Arvidsson U, Dado RJ, Chakrabarti S, Lee JH, Nakano AH, Dado RJ, Loh HH, Law PY, Wessendorf MW, Elde RJ (1995) Distribution and targeting of a $\mu$-opioid receptor (MOR1) in brain and spinal cord. J Neurosci 15:3328-3341.

Beitz AJ, Larson AA, Monaghan P, Altschuler RA, Mullett MM, Madl JE (1986) Immunohistochemical localization of glutamate, glutaminase and aspartate aminotransferase in neurons of the pontine nuclei of the rat. Neuroscience 17:741-753.

Browning KN, Travagli RA (1999) Characterization of the in vitro effects of 5-hydroxytryptamine $(5 \mathrm{HT})$ on identified neurones of the rat dorsal motor nucleus of the vagus (DMV). $\mathrm{Br} \mathrm{J}$ Pharmacol 128:1307-1315.

Browning KN, Travagli RA (2000) Opioid peptides in the rat dorsal motor nucleus of the vagus (DMV) inhibit excitatory but not inhibitory synaptic transmission. Soc Neurosci Abstr 26:1684

Browning KN, Travagli RA (2001) The peptide TRH uncovers the presence of presynaptic 5-HT1A receptors via activation of a second messenger pathway in the rat dorsal vagal complex. J Physiol (Lond) 531:425-435.

Browning KN, Renehan WE, Travagli RA (1999) Electrophysiological and morphological heterogeneity of rat dorsal vagal neurones which project to specific areas of the gastrointestinal tract. J Physiol (Lond) 517:521-532.

Bueno L, Fioramonti J, Honde C, Fargeas MJ, Primi MP (1985) Central and peripheral control of gastrointestinal and colonic motility by endogenous opiates in conscious dogs. Gastroenterology 88:549-556.

Burks TF, Galligan JJ, Hirning LD, Porreca F (1987) Brain, spinal cord and peripheral site of action of enkephalins and other endogenous opioids on gastrointestinal motility. Gastroenterol Clin Biol 11:44B-51B.

Cheng PY, Liu-Chen LY, Chen C, Pickel VM (1996) Immunolabeling of mu opioid receptors in the rat nucleus of the solitary tract: extrasynaptic plasmalemmal localization and association with $\mathrm{Leu}^{5}$ enkaphalin. J Comp Neurol 371:522-536.

D'Amelio FE, Mehler WR, Gibbs MA, Eng LF, Wu JY (1987) Immunocy tochemical localization of glutamic acid decarboxylase (GAD) and glutamine synthetase (GS) in the area postrema of the cat: light and electron microscopy. Brain Res 410:232-244.

Dashwood MR, Muddle JR, Spyer KM (1988) Opiate receptor subtypes in the nucleus tractus solitarii of the cat: the effect of vagal section. Eur J Pharmacol 155:85-92. 
Del Tacca M, Bernadini C, Corsano E, Soldani G, Rozé C (1987) Effects of morphine on gastric ulceration, barrier mucus and acid secretion in pylorus-ligated rats. Pharmacology 35:174-180.

Ding YQ, Kaneko T, Nomura S, Mizuno N (1996) Immunohistochemical localization of $\mu$-opioid receptors in the central nervous system of the rat. J Comp Neurol 367:375-402.

Duan S, Shimizu N, Fukuda A, Hori T, Oomura Y (1990) Hyperpolarizing action of enkephalin on neurons in the dorsal motor nucleus of the vagus, in vitro. Brain Res Bull 25:551-559.

Farkas E, Jansen ASP, Loewy AD (1997) Periaqueductal gray matter projection to vagal preganglionic neurons and the nucleus tractus solitarius. Brain Res 764:257-261.

Fox DA, Burks TF (1988) Roles of central and peripheral mu, delta, and kappa opioid receptors in the mediation gastric acid secretory effects in the rat. J Pharmacol Exp Ther 244:456-462.

Fox EA, Powley TL (1985) Longitudinal columnar organization within the dorsal motor nucleus represents separate branches of the abdominal vagus. Brain Res 341:269-282.

Gillis RA, Quest JA, Pagani FD, Norman WP (1989) Control centers in the central nervous system for regulating gastrointestinal motility. In: Handbook of Physiology, Section 6, The gastrointestinal system motility and circulation, Vol 1, part 2 (Wood JD, ed), pp 621-683. Bethesda, MD: American Physiological Society.

Giraudo SQ, Kotz M, Billington CJ, Levine AS (1998) Association between the amygdala and the nucleus of the solitary tract in $\mu$-opioid induced feeding in the rat. Brain Res 802:184-188.

Gue M, Junien JL, Bueno L (1989) Central and peripheral opioid modulation of gastric relaxation induced by feeding in dogs. J Pharmacol Exp Ther 250:1006-1010.

Guo JJ, Browning KN, Rogers RC, Travagli RA (2001) Catecholaminergic neurons in rat dorsal motor nucleus of vagus project selectively to gastric corpus. Am J Physiol Gastrointest Liver Physiol 280:G361-G367.

Hayar A, Guyenet PG (1998) Pre- and post-synaptic inhibitory actions of methionine-enkephalin on identified bulbospinal neurons of the rat RV L. J Neurophysiol 80:2003-2014.

Hirai K, Katayama Y (1985) Effect of the endogenous analgesis dipeptide, kyotorphin, on transmitter release in sympathetic ganglia. $\mathrm{Br} \mathrm{J}$ Pharmacol 85:629-634.

Huang J, Wang H, Pickel VM (2000) Rostrocaudal variation in targeting of $N$-methyl-D-aspartate and mu-opioid receptors in the rat medial nucleus of the solitary tract. J Comp Neurol 421:400-411.

Johnson GD, Nogueira-Araujo GM (1981) A simple method of reducing the fading of immunofluorescence during microscopy. J Immunol Methods 43:349-350.

Kalyuzhny AE, Wessendorf MW (1997) CNS GABA neurons express the mu-opioid receptor: immunocytochemical studies. NeuroReport 8:3367-3372

Kotz CM, Billington CJ, Levine AS (1997) Opioids in the nucleus of the solitary tract are involved in feeding in the rat. Am J Physiol 272:R1028-R1032.

Kotz CM, Glass MJ, Levine AS, Billington CJ (2000) Regional effect of naltrexone in the nucleus of the solitary tract in blockade of NPYinduced feeding. Am J Physiol Regul Integr Comp Physiol 278:R499-R503.

Krowicki ZK, Moerschbaecher JM, Hornby PJ (1999) Dorsal vagal complex is a site for inhibitory gastric motor and cardiovascular effects of morphine. Gastroenterology 116:A619.

Liubashina O, Jolkkonen E, Pitkanen A (2000) Projections from the central nucleus of the amygdala to the gastric related area of the dorsal vagal complex: a Phaseolus vulgaris-leucoagglutinin study in rats. Neurosci Lett 291:85-88.

Maley BE (1996) Immunohistochemical localization of neuropeptides and neurotransmitters in the nucleus solitarius. Chem Senses 21:367-376

Mansour A, Fox CA, Burke S, Akil H, Watson SJ (1995) Immunohistochemical localization of the cloned $\mu$-opioid receptor in the rat CNS. J Chem Neuroanat 8:283-305.

McCann MJ, Rogers RC (1992) Impact of antral mechanoreceptor activation on the vago-vagal reflex in the rat: functional zonation of responses. J Physiol (Lond) 453:401-411.

Morilak DA, Somogyi P, McIlhinney RA, Chalmers J (1989) An enkephalin-containing pathway from nucleus tractus solitarius to the pressor area of the rostral ventrolateral medulla of the rabbit. Neuroscience 31:187-194.

Pickel VM, Chan J, Milner TA (1989) Ultrastructural basis for interactions between central opioids and catecholamines. II. Nuclei of the solitary tracts. J Neurosci 9:2519-2535.

Pickel VM, Aicher SA, Aoki C, Cheng PY, Nirenberg MJ (1998) Catecholamines, opioids, and vagal afferents in the nucleus of the solitary tract. Adv Pharmacol 42:642-645.

Rackham A, Wood PL, Hudgin RL (1982) Kyotorphin (tyrosine-arginine): further evidence for indirect opiate receptor activation. Life Sci 30:1337-1342.

Rhim H, Miller RJ (1994) Opioid receptors modulate diverse types of calcium channels in the nucleus tractus solitarius of the rat. J Neurosci 14:7608-7615.

Rhim H, Toth PT, Miller RJ (1996) Mechanism of inhibition of calcium channels in rat nucleus tractus solitarius by neurotransmitters. Br J Pharmacol 118:1341-1350.

Rogers RC, McTigue DM, Hermann GE (1995) Vagovagal reflex control of digestion: afferent modulation by neural and "endoneurocrine" factors. Am J Physiol 268:G1-G10.

Rogers RC, Hermann GE, Travagli RA (1999) Brainstem pathways responsible for oesophageal control of gastric motility and tone in the rat. J Physiol (Lond) 514:369-383.

Shiomi H, Kuraishi Y, Ueda H, Harada Y, Amano H, Takagi H (1981) Mechanism of kyotorphin-induced release of met-enkephalin from guinea-pig striatum and spinal cord. Brain Res 221:161-169.

Sivarao DV, Krowicki ZK, Hornby PJ (1998) Role of GABA receptors in rat hindbrain nuclei controlling gastric motor function. Neurogastroenterol Motil 10:305-313.

Travagli RA, Gillis RA (1994) Nitric oxide-mediated excitatory effect on neurons of dorsal motor nucleus of vagus. Am J Physio 266:G154-G160.

Travagli RA, Williams JT (1996) Endogenous monoamines inhibit glutamate transmission in the spinal trigeminal nucleus of the guinea pig. J Physiol (Lond) 491:177-185.

Travagli RA, Gillis RA, Rossiter CD, Vicini S (1991) Glutamate and GABA-mediated synaptic currents in neurons of the rat dorsal motor nucleus of the vagus. Am J Physiol 260:G531-G536.

Travagli RA, Gillis RA, Vicini S (1992) Effects of thyrotropin-releasing hormone on neurons in rat dorsal motor nucleus of the vagus, in vitro. Am J Physiol 263:G508-G517.

Ueda H, Yoshihara Y, Takagi H (1986) A putative met-enkephalin releaser, kyotorphin, enhances intracellular $\mathrm{Ca}^{2+}$ in the synaptosomes. Biochem Biophys Res Commun 137:897-902.

Willis A, Mihalevich M, Neff RA, Mendelowitz D (1996) Three types of postsynaptic glutamatergic receptors are activated in DMNX neurons during stimulation of NTS. Am J Physiol 271:R1614-R1619.

Xia Y, Haddad GG (1991) Ontogeny and distribution of opioid receptors in the rat brainstem. Brain Res 549:181-193.

Zheng ZL, Rogers RC, Travagli RA (1999) Selective gastric projections of nitric oxide synthase-containing vagal brainstem neurons. Neuroscience 90:685-694. 